\title{
Analysis of Secondary V(D)J Rearrangements in Mature, Peripheral T Cells of Ataxia-Telangiectasia Heterozygotes
}

\author{
Erica Lantelme, Valentina Turinetto, Stefania Mantovani, Antonietta Marchi, \\ Silvia Regazzoni, Paola Porcedda, Mario De Marchi, and Claudia Giachino \\ Department of Clinical and Biological Sciences (EL, VT, SR, PP, MDeM, CG), University of Turin, Orbassano, and \\ Laboratory of Experimental Immunology (SM, CG), IRCCS Salvatore Maugeri Foundation, Pavia, and Department \\ of Pediatric Sciences (AM), University of Pavia, IRCCS Policlinico San Matteo, Pavia, Italy
}

SUMMARY: Ataxia-telangiectasia (AT) is a rare recessive disease with pleiotropic involvement of the nervous and lymphoid systems. AT heterozygotes have a population frequency of about $1 \%$, and although not manifesting any overt clinical symptoms, they have an increased mortality, mainly because of cancer and ischemic heart disease. We and others have described a mature T lymphocyte population with an altered T cell receptor surface expression ("TCR variant") that reactivates the recombination activating genes (RAG) and is expanded in the blood of patients with AT. In view of the known role of $V(D) J$ recombination in the onset of tumorigenic translocations, we proposed that the increased RAG activity was responsible for the predisposition of AT homozygotes to develop mature-type T leukemia/lymphoma. In the present report, we used cytofluorimetry to quantify the TCR variant population and the memory/naïve T-cell compartments in the blood of AT heterozygotes compared with AT patients and controls. We assessed the expression of different recombinase genes through RT-PCR/oligotyping and cytofluorometric analysis and searched for rearrangement intermediates by ligase-mediated PCR in T-cell lines from four heterozygous carriers. We found the TCR variant population was increased on average $2 \times$ in AT heterozygotes (vs 10× in homozygotes) compared with controls, and naïve $\mathrm{CD}^{+} \mathrm{T}$ lymphocytes were reduced on average $0.5 \times$ (vs $0.1 \times$ in homozygotes). We were able to demonstrate recombinase gene expression in all four heterozygous T-cell lines, and rearrangement intermediates, indicative of ongoing $V(D) J$ recombination, in two. These rearrangements were compatible with V-gene replacement, a mechanism of receptor editing described for $\lg$ and $\mathrm{TCR} \alpha$ genes, to our knowledge not previously documented for TCR $\beta$. In conclusion, we found that RAG reactivation and secondary V(D)J rearrangements, potential risk factors of mature-type leukemia in AT homozygotes, also take place in AT heterozygous carriers and might place this large population fraction at an increased risk of leukemia/lymphoma. (Lab Invest 2003, 83:1467-1475).

\begin{abstract}
$F$ vidence supports the existence among peripheral C T lymphocytes of a variant subpopulation with an altered TCR surface expression $\left(\mathrm{CD} 4^{+} \mathrm{CD} 3^{\text {low }}\right)$ in which recombination activating genes (RAG) are expressed. We and others observed functional RAG gene products in mature $T$ cells with defective TCR expression (Lantelme et al, 2000b; McMahan and Fink, 1998), and we showed that these T cells were increased in number in patients with ataxiatelangiectasia (AT) and Nijmegen breakage syndrome (Lantelme et al, 2000a), both autosomal recessive chromosomal instability syndromes characterized by immunodeficiency, hypersensitivity to ionizing radiation, defective DNA repair, and predisposition to de-
\end{abstract}

DOI: 10.1097/01.LAB.0000092228.51605.6A

Received June 25, 2003.

This work was partially supported by an ONLUS Fondazione Bertolini Torino and PRIN grant from Italian MIUR. SM is supported by a fellowship from the European School of Oncology.

Address reprint requests to: Dr. C. Giachino, Department of Clinical and Biological Sciences, Regione Gonzole 10, 10043 Orbassano (TO), Italy.

E-mail claudia.giachino@unito.it velop lymphoid malignancies (Lavin and Shiloh, 1997; Shiloh, 1997). The finding of RAG gene expression in this TCR variant subpopulation suggests that secondary $V(D) J$ rearrangements may occur physiologically to rescue their defective phenotype and cellular function. On the other hand, it has long been assumed that illegitimate recombination events promoted by RAG genes can cause the chromosomal translocations observed in various lymphoid neoplasias (Bakhshi et al, 1987; Haluska et al, 1986; Rabbitts, 1994; Tycko and Sklar, 1990). Indeed, an important clinical feature of patients with AT and Nijmegen breakage syndrome is the high incidence of T lymphomas carrying translocations and inversions of chromosomes 7 and 14 at the TCR $\alpha$ and TCR $\beta$ loci (Lavin and Shiloh, 1997; Shiloh, 1997; Taylor et al, 1996). The role of V(D)J recombination in the onset of tumorigenic translocations in these patients is also supported by knock-out mouse models in which the inactivation of RAG genes either abolishes (Liao and Van Dyke, 1999) or reduces (Petiniot et al, 2000) the risk of thymic lymphoma associated with the ATM null genotype. Recent evidence that RAG proteins can mediate DNA transposition-like events both in vitro (Agrawal et al, 
1998; Hiom et al, 1998) and in vivo (Messier et al, 2003) further supports this hypothesis. Based on these findings, we proposed a possible association of altered TCR expression with RAG activity and the frequent leukemogenic translocations in AT patients (Lantelme et al, 2000a).

While homozygotes are rare, AT heterozygotes account for about $1 \%$ of births in the general population (Swift, 2001). Although they are healthy, epidemiologic data indicate an increased mortality rate compared with noncarriers mainly because of cancer and ischemic heart disease (Su and Swift, 2000). Cells from heterozygous carriers show both phenotypical and functional features intermediate between those of AT homozygotes and normal individuals. In many cases they express almost halved levels of ATM protein (Delia et al, 2000) and display an intermediate sensitivity to in vitro irradiation, impaired cell cycle arrest (Barlow et al, 1999; West et al, 1995; Xu and Baltimore, 1996), decreased radiation-induced apoptosis (Bebb et al, 2001), and increased chromosomal damage (Neubauer et al, 2002) in comparison with control cells. A recent expression array analysis of the irradiation response in cells from AT heterozygotes revealed a pattern that differed from normal cells in the expression of several genes involved in proliferation, apoptosis, and cell cycle regulation (Watts et al, 2002). Moreover, the ATM heterozygous genotype has been associated with high spontaneous chromosomal instability in humans as detected by whole-paint fluorescence in situ hybridization (Stumm et al, 2001) and with a higher sensitivity to radiation oncogenesis in a mouse ATM model (Smilenov et al, 2001).

In the present report, we have assessed whether recombinase genes reactivation and secondary $\mathrm{V}(\mathrm{D}) \mathrm{J}$ rearrangements, which are probably involved in mature-type leukemia in AT homozygotes, also take place in AT heterozygous carriers and might place them at an increased risk of developing cancer.

\section{Results}

\section{Relative Frequencies of $\mathrm{CD} 4^{+} \mathrm{CD} 3^{\text {low }}$ TCR Variants}

We quantified the $\mathrm{CD} 4^{+} \mathrm{CD} 3^{\text {low }}$ TCR variants in the peripheral blood mononuclear cells (PBMC) of $10 \mathrm{AT}$ heterozygotes and 10 AT patients using double fluorescence staining with anti-CD3 and anti-CD4 mAbs. The average number of $\mathrm{CD} 4^{+} \mathrm{CD} 3^{\text {low }}$ cells in AT heterozygotes was $6.0 \times 10^{-4}$, a significant increase from the $2.4 \times 10^{-4}$ level previously found in normal donors ( $p<0.05$ using the Student's $t$ test) (Akiyama et al, 1995; Kyoizumi et al, 1990; Lantelme et al, 2000a) (Fig. 1) but lower than the level in AT patients (mean, $31.8 \times 10^{-4} ; p<0.001$ ) (Fig. 1). The high number of $\mathrm{CD} 4^{+} \mathrm{CD} 3^{\text {low }}$ cells was confirmed in a second blood sample that we obtained 2 years after the first assay from 5 of the 10 AT patients: the absolute proportion of variant cells could change, generally increasing their number (four of five samples), yet without significantly modifying the average value reported above (not shown). T-cell lines, estab-

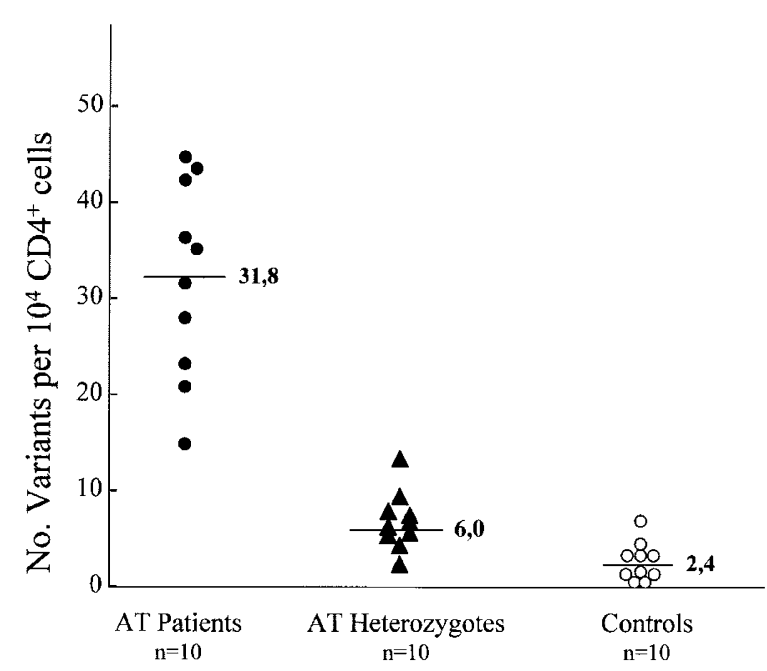

Figure 1.

Increased frequency of variant $C D 4^{+} C D 3^{\text {low }} T$ cells in the peripheral blood of ataxia-telangiectasia (AT) heterozygous carriers. Peripheral blood mononuclear cells (PBMC; $1 \times 10^{6}$ ) from 10 AT patients (age range, 2-17 years), 10 AT heterozygotes ( $30-55$ years), and 10 normal donors ( $26-55$ years) were stained with anti-CD4 and anti-CD3 mAbs, and the variant $\mathrm{CD} 4{ }^{+} \mathrm{CD}^{\text {low }} \mathrm{T}$-cell frequencies were determined as previously described (Hirota et al, 1994). The mean of the TCR variant cells found in each group is shown.

lished from the PBMC of four heterozygous carriers, were also analyzed and found to contain TCR variant cells. However, in accordance with previous results (Lantelme et al, 2000a), we noticed that the frequency of variant cells in the T-cell lines derived from three of the four subjects was lower than in the PBMC of the same patients without stimulation (from $7.2 \times 10^{-3}$ in Pt10-PBMC to $3.7 \times 10^{-4}$ in the corresponding PHA line; from $5.6 \times 10^{-4}$ in $\mathrm{Ht} 10-\mathrm{m}-\mathrm{PBMC}$ to $1.4 \times 10^{-4}$ in the PHA line; from $13 \times 10^{-4}$ in Ht10-f-PBMC to 9 $\times 10^{-5}$ in the PHA line). One likely explanation for this difference is that the intrinsic growth disadvantage of the mutant cells could be enhanced by strong proliferative stimuli such as that provided by PHA.

\section{Selective Decrease in Circulating $\mathrm{CD4}^{+} \mathrm{T}$ Cells with a Naïve Phenotype}

It has been reported that AT patients have a selective deficiency of naïve CD4 ${ }^{+} \mathrm{T}$ lymphocytes (Giovannetti et al, 2002; Paganelli et al, 1992). Phenotypic analysis performed in five patients with AT allowed us to confirm a considerable decrease in the percentage of circulating $\mathrm{CD}^{+}{ }^{+} \mathrm{CD}_{45 \mathrm{RA}}{ }^{+}$(naïve) $\mathrm{T}$ cells in all cases (mean \pm SD, $3.8 \pm 2.2 \%$ ) (Fig. $2 A)$. Interestingly, we found a diminished amount of $\mathrm{CD}^{+}$naïve $\mathrm{T}$ cells also in AT heterozygotes (mean \pm SD, $19.6 \pm 13.7 \%$ ) (Fig. 2A). To assess whether this decrease was statistically significant, we used the Student's $t$ test to compare values obtained in the heterozygotes with those found in normal, healthy subjects. Because the relative lymphocyte subpopulation frequencies are significantly affected by age, we analyzed the naïve CD4 subset in four healthy individuals with a distribution of age similar to that of our AT heterozygotes (30-55 years old). The percentages of $C D 4{ }^{+} \mathrm{CD}_{4} \mathrm{RA}{ }^{+}$cells found 
A

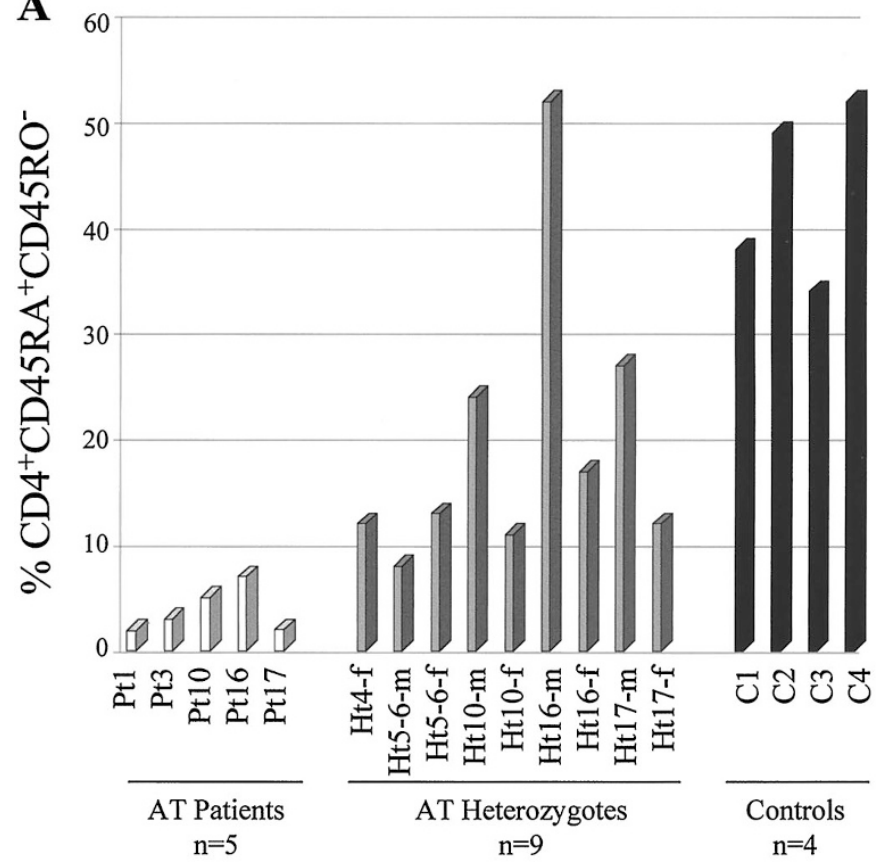

B 7

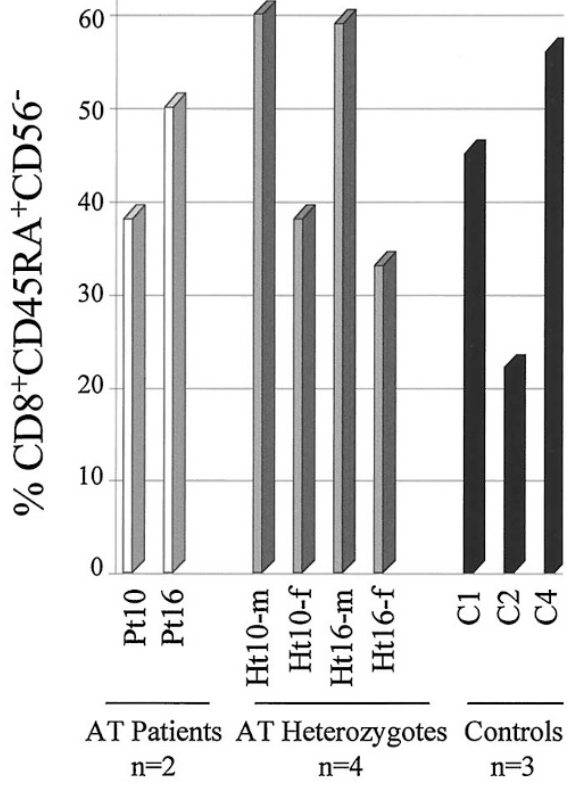

Figure 2.

Decreased production of naïve CD4 ${ }^{+} \mathrm{T}$ cells in AT heterozygotes. A, PBMC from five AT patients, nine AT heterozygotes, and four normal controls were analyzed by triple staining with anti-CD4, anti-CD45RA, and anti-CD45RO mAbs. Bars indicate the percentages of naïve T cells within the CD4bright population. The mean \pm SD was $3.8 \pm 2.2 \%$ for the AT patients, $19.6 \pm 13.7 \%$ for the AT heterozygotes, and $42.2 \pm 8.6 \%$ for the controls. The percentage of CD4 naïve T cells in both AT patients and AT heterozygotes was significantly diminished compared with normal controls $(p<0.001$ and $p<0.01$, respectively). B, The percentage of CD8 naïve T cells was determined in two AT patients, four AT heterozygotes, and three controls by triple staining with anti-CD8, anti-CD45RA, and anti-CD56 mAbs. Bars indicate the percentages of cells with the CD8 ${ }^{\text {bright }}{ }^{2}$ D45RA ${ }^{\text {bright }} \mathrm{CD}_{56}{ }^{-}$naïve phenotype. $P t=$ patient; $H t=$ heterozygote; $m=$ mother; $f=$ father; $C=$ control.

in these normal controls (mean $\pm \mathrm{SD}, 42.2 \pm 8.6 \%$ ) (Fig. 2A) were within the range reported by other authors for healthy subjects belonging to this age group (Isoda et al, 2002). We found a significantly diminished amount of $\mathrm{CD}^{+}$naïve T cells in AT heterozygotes versus normal donors $(p<0.01)$, with only one heterozygous subject ( $\mathrm{Ht} 16-\mathrm{m}$, Fig. 2A) showing a normally sized CD4 naïve compartment.

Recently, significantly diminished levels have been shown not only for $\mathrm{CD}^{+}$but also $\mathrm{CD}^{+}$naïve $\mathrm{T}$ lymphocytes in AT patients (Schubert et al, 2002). To assess whether AT heterozygotes presented this CD8 naïve deficiency, we performed triple-fluorescence stainings using anti-CD8/CD45RA/CD45RO mAb combinations. When we defined the percentage of CD8 ${ }^{\text {bright }} C D 45 R A^{\text {bright }} C D 45 \mathrm{RO}^{-}$cells, we found a slightly decreased number of CD8 naïve T cells in one of two AT patients analyzed but in none of four heterozygous carriers (not shown). At variance with the $\mathrm{CD}^{+}$cells, $\mathrm{CD}^{+} \mathrm{T}$ lymphocytes with the $\mathrm{CD}_{45 \mathrm{RA}}{ }^{\text {bright }} \mathrm{CD} 45 \mathrm{RO}^{-}$phenotype include both naïve and effector T cells. We then used the anti-CD56 in conjunction with anti-CD8 and anti-CD45RA mAbs in triple-fluorescence experiments to further distinguish between the $\mathrm{CD} 8^{\text {bright }} \mathrm{CD} 45 \mathrm{R} \mathrm{A}^{\text {bright }} \mathrm{CD} 56^{-}$, true naïve $T$ cells and the CD8 ${ }^{\text {bright }} \mathrm{CD} 45 \mathrm{R} \mathrm{A}^{\text {bright }} \mathrm{CD} 56^{+}$, effector $T$ cells, in accordance with the method of Pittet et al, (2000). Again, we found that the CD8 naiive compartment in four AT heterozygotes as well as in three age-matched control subjects (Fig. 2B) was com- prised within the mean value reported by Isoda et al (2002) for healthy subjects belonging to the same age group (mean \pm SD, $41 \pm 26.8 \%$ ).

\section{Recombinase Gene Expression and Ongoing TCR Gene Rearrangements}

T-cell lines established from four heterozygous carriers were used to assess whether it was possible to detect the expression of different recombinase genes. Using intron-spanning primers specific for RAG-1, RAG-2, and TdT genes and a combination of RT-PCR and Southern blotting analyses, we detected the expression of at least two of the three recombinase genes in all of the analyzed cases (Fig. 3A). FACS analysis on permeabilized $T$ cells using an anti-human TdT Ab confirmed the presence of a small fraction of TdT-expressing cells within the heterozygous lines ( 0.01 to $0.02 \%$ vs $0.00 \%$ calculated in three normal control T-cell lines) (Fig. 3B).

To assess whether the recombination-associated proteins expressed by $\mathrm{T}$ lymphocytes from AT heterozygotes were capable of activating the $V(D) J$ recombination, we used the sensitive and highly specific ligase-mediated PCR assay (Schlissel et al, 1993). We searched for rearrangement intermediates, ie, doublestranded signal end (SE) breaks, in the TCR $\beta$ locus using primers specific for the $5^{\prime}$ and $3^{\prime}$ terminus of both $\mathrm{D} \beta-1$ and $\mathrm{D} \beta-2$. The presence of SE intermediates is a stringent test for RAG activity because 


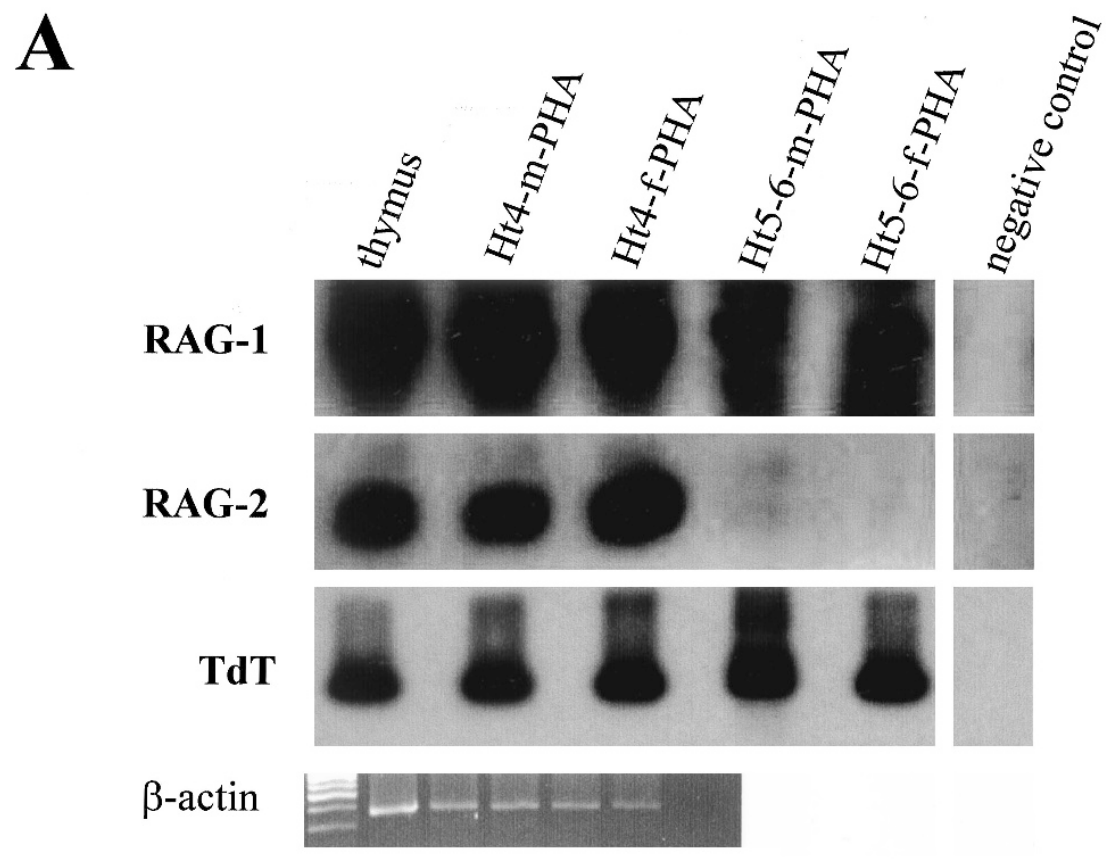

B

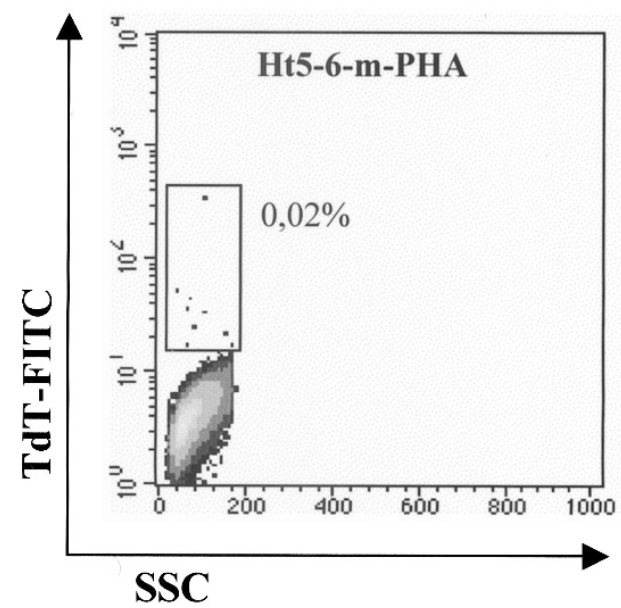

Figure 3.

Recombinase gene expression in T-cell lines from AT heterozygotes. A, Expression of recombination activating genes 1 and 2 (RAG-1, RAG-2) and TdT gene was assessed in T-cell lines from four AT heterozygous carriers by a combination of RT-PCR, nested PCR, and Southern blotting. cDNA was amplified with specific oligonucleotides, and the corresponding products were blotted and hybridized with internal primers. In the first lane, human fetal thymus cDNA was used as positive control, whereas the last lane represents the negative control with no CDNA. The ethidium bromide-stained gel at the bottom of the panel shows the $\beta$-actin RT-PCR products ( 40 cycles) as a control of cDNA integrity. B, T-cell lines established from six heterozygous carriers were permeabilized and stained with an anti-human TdT $\mathrm{Ab}$. The percentage of $\mathrm{TdT}^{+}$cells inside the lines varied between $0.01 \%$ and $0.02 \%(0.00 \%$ in three normal control lines). Shown is one representative case.

recombination requires not only functional RAG-1 and RAG-2 proteins but also DNA accessibility. As expected, SE breaks associated with all four sites were detected in human thymic DNA (Fig. 4, lanes 6) but not in the negative control (no DNA, lanes 5). Interestingly, SE breaks associated with the $5^{\prime}$ side of $D \beta-1$ were detected in the T-cell line of Ht5-6-f (lanes 4) and SE breaks associated with the $5^{\prime}$ side of $\mathrm{D} \beta-2$ were detected in the T-cell line of $\mathrm{Ht} 4$-f (lanes 2). Taken together, these data indicate the presence of ongoing rearrangements at the TCR $\beta$ locus in two of the four heterozygote T-cell lines analyzed. In both cases, a partial V to D-J rearrangement was evidenced.

\section{Discussion}

We previously reported that variant $\mathrm{T}$ lymphocytes losing antigen receptor expression were capable of 


\section{$\mathrm{D} \beta-1 \quad \mathrm{D} \beta-2$}

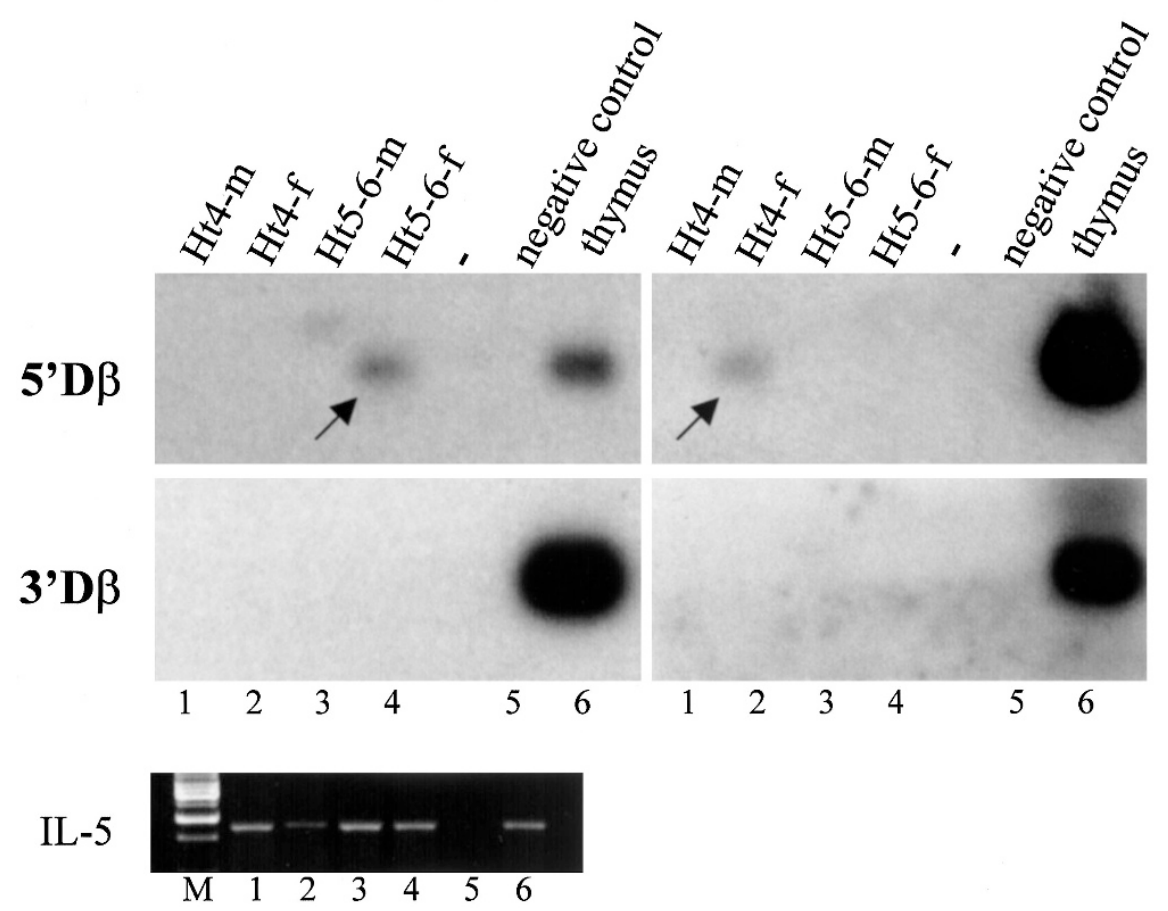

Figure 4.

Ongoing rearrangements of TCR genes in T-cell lines from AT heterozygous carriers. LM-PCR assay was used to assess the presence of functional RAG proteins capable of initiating V(D)J recombination in the T-cell lines from AT heterozygotes. Genomic DNA from human fetal thymus (positive control, lanes 6) and from the T-cell lines established from four AT heterozygous carriers (lanes 1-4) was ligated to the BW linker as described (Schlissel et al, 1993) and used as a template in PCR reactions with primers to detect signal ends associated with $D \beta-1$ (5'D $\beta-1$ and $\left.3^{\prime} D \beta-1\right)$ and $D \beta-2\left(5^{\prime} D \beta-2\right.$ and $\left.3^{\prime} D \beta-2\right)$. The PCR samples were blotted, and each filter was hybridized with two different specific internal oligonucleotides. Lanes 5, negative controls, no DNA. Exposure lengths were 7 days for $3^{\prime} D \beta-2,1.5$ hours for 5 ' $D \beta-1$, and 3 hours for the other two sites. Control PCR reactions with IL-5 gene primers are shown as an ethidium bromide-stained gel ( $30 \mathrm{cycles}) . M=$ marker (1-kb DNA ladder).

expressing RAG genes and of undergoing secondary $\mathrm{V}(\mathrm{D}) \mathrm{J}$ rearrangements (Lantelme et al, 2000b), and we observed that these variant $T$ cells accumulate in the peripheral blood of patients with genetic instability syndromes (AT and Nijmegen breakage syndrome) (Lantelme et al, 2000a). In the present report, we found an increase of this variant T lymphocyte subpopulation even in the peripheral blood of AT heterozygotes that was on average doubled compared with normal controls. Moreover, we demonstrated recombinase gene expression in all four T-cell lines analyzed and the presence of rearrangement intermediates in two, which indicates that secondary $V(D) J$ recombination events take place in some mature $T$ lymphocytes from AT heterozygous carriers. It seems probable that the process occurs in the variant subpopulation, although we have no direct experimental proof, but only indirect evidence, of this. In fact, our findings confirm and extend previous observations in both mice and humans indicating that secondary $\mathrm{V}(\mathrm{D}) \mathrm{J}$ rearrangements can occur in mature $T$ cells in response to the loss of antigen receptor (Lantelme et al, 2002a, 2000b; McMahan and Fink, 1998).

Receptor editing is a well-described phenomenon operating at various stages of the immune response. In bone marrow cells it is thought to serve B-cell tolerance and antibody diversification functions (Radic et al, 1993; Radic and Zouali, 1996; Tiegs et al, 1993), whereas in germinal center B cells (Han et al, 1997; Papavasiliou et al, 1997; Rajewsky, 1998) and peripheral T lymphocytes with decreased antigen receptor surface expression (Lantelme et al, 2000b; McMahan and Fink, 1998), the similar phenomenon of receptor revision would mainly contribute to repertoire diversification. On the basis of our work, this mechanism now seems to be active at a higher rate not only in peripheral T cells of patients with AT (Lantelme et al, 2000a) but also of AT heterozygotes. Notably, both AT homozygotes (Giovannetti et al, 2002; Paganelli et al, 1992; and this work) and, to a lesser extent, AT heterozygotes (this work) have a selective decrease in circulating $\mathrm{CD}^{+}{ }^{+} \mathrm{T}$ lymphocytes with a naïve phenotype. Thus, the contribution of secondary TCR rearrangements to peripheral TCR repertoire diversification in AT homozygotes and heterozygotes may be even more important to compensate a reduced thymic output of new TCR specificities.

In two of four T-cell lines established from AT heterozygous carriers, we could demonstrate $V(D) J$ recombination intermediates associated with recombinase gene expression, indicative of ongoing recombination events. Interestingly, in both cases these ongoing recombination events corresponded to partial $V$ to D-J rearrangements, a phenomenon known as $\mathrm{V}$-gene replacement that changes the antigen combining site by replacing a portion of the original $V(D) J$ 
rearrangement with the corresponding portion of a new $\mathrm{V}$ segment. This mechanism had already been described in receptor revision of both immunoglobulins and T cells (Golub, 2002; Golub et al, 2001; Itoh et al, 2000), although in this latter case it was limited to the TCR $\alpha$ locus. To our knowledge, this is the first report in which evidence of $\mathrm{V}$-gene replacement, although indirect, is presented in the case of TCR $\beta$.

On the basis of the increased risk of chromosomal rearrangements in $\mathrm{T}$ lymphocytes - a hallmark of AT patients (Taylor et al, 1996)_and of the known role of $\mathrm{V}(\mathrm{D}) \mathrm{J}$ recombination in the onset of tumorigenic translocations in AT, we proposed a possible relationship between the augmented RAG-expressing T-cell subpopulation we documented in AT homozygotes and their increased predisposition to develop mature-type T leukemia/lymphoma (Lantelme et al, 2000a). Similarly, the higher proportion of variant $T$ cells and the secondary $\mathrm{V}(\mathrm{D}) \mathrm{J}$ rearrangements observed in AT heterozygous carriers might bear a risk for them as well, albeit a weaker one. A significantly increased predisposition in AT heterozygotes has been demonstrated by epidemiologic studies for breast cancer only (Khanna, 2000), but lung, gastric and, notably, lymphoid tumors have also been reported to occur at higher frequencies than expected in these subjects (Swift et al, 1991). The leukemogenic risk linked to ionizing radiation is well known as is the fact that cells from AT heterozygotes are more sensitive than normal cells to this agent (Barlow et al, 1999; Bebb et al, 2001; Neubauer et al, 2002; West et al, 1995; Xu and Baltimore, 1996). In addition, up to half of the individuals who contract T-cell prolymphocytic leukemia, a rare aggressive mature $\mathrm{T}$-cell leukemia with similarities to the mature $\mathrm{T}$ leukemia seen in patients with AT, are heterozygous carriers of mutations in the ATM gene (Boultwood, 2001; Stoppa-Lyonnet et al, 1998; Vorechovsky et al, 1997; Yuille et al, 1998) with loss of the normal ATM allele in leukemic cells. This suggests that ATM functions as a classic tumor suppressor in this context (Boultwood, 2001).

Increased recombination becomes dangerous in particular if associated with a decrease of other ATM functions essential for the DNA damage response. The relationships between ATM haploinsufficiency and leukemia/lymphoma are not definitively settled, and there is presently a consensus that more data are necessary (Geoffroy-Perez et al, 2001). It will be of interest to assess whether the different functions through which ATM could ensure genetic safety during V(D)J recombination (ie, control of chromatin accessibility at specific loci, phosphorylation of the minor histone $\mathrm{H} 2 \mathrm{AX}$, and regulation of apoptosis in mature lymphocytes containing DSBs) are affected in heterozygote cells as a consequence of the decreased ATM dose.

\section{Materials and Methods}

\section{Patients, Cells, and FACS Staining}

PBMC were obtained from 10 AT patients and 10 obligate AT carriers (parents of AT homozygotes) by
Ficoll-Paque Plus (Amersham Pharmacia Biotech, Uppsala, Sweden) density gradient centrifugation. T-cell lines were derived by culturing PBMC in complete RPMI 1640 supplemented with $5 \%$ human serum (EuroClone Ltd., United Kingdom) and $1 \mu \mathrm{g} / \mathrm{ml}$ PHA. A total of $20 \mathrm{U} / \mathrm{ml}$ recombinant IL-2 was added on Day 5 . The lines were maintained by periodic stimulation with PHA $(1 \mu \mathrm{g} / \mathrm{ml})$ and irradiated allogeneic PBMC in complete RPMI medium supplemented with $5 \%$ human serum and $200 \mathrm{U} / \mathrm{ml}$ recombinant IL-2.

Indirect double stainings using anti-human CD3 (OKT3, IgG2a) and anti-human CD4 (6D10, IgG1) mAbs were performed to quantify the $\mathrm{CD} 4^{+} \mathrm{CD} 3^{\text {low }}$ cells, using phycoerythrin (PE)-labeled goat antimouse IgG2a and FITC-labeled goat anti-mouse IgG1 (Southern Biotechnology Associates, Inc., Birmingham, Alabama) as second Abs. CD4 naïve T cells were analyzed by triple staining with anti-CD4-PE, antiCD45RO-FITC, and anti-CD45RA-CyChrome (all from BD PharMingen, San Diego, California). CD8 naïve T cells were checked with two triple stainings with anti-CD8-PE (BD PharMingen), anti-CD45RACyChrome, and either anti-CD45RO-FITC or antiCD56-FITC (Southern Biotechnology Associates, Inc.). The staining with anti-TdT-FITC (Becton Dickinson, San Jose, California) was performed on cell lines fixed and permeabilized with the Cytofix/Citoperm Kit (BD Biosciences PharMingen) following the manufacturer's instruction; cell lines were incubated at room temperature for 30 minutes. The stained cells were analyzed by flow cytometry on a FACScalibur (Becton Dickinson) with CELLQUEST software.

\section{Quantification of $\mathrm{CD}^{+} \mathrm{CD}^{\text {low }} \mathrm{T}$ Lymphocytes}

The frequency of variant cells was determined as described by Hirota et al (1994). Briefly, the lymphocyte fraction was gated by forward and side scatter and a window for variant cells was set in the region where the surface CD3 level was $<1 / 25$ th that of normal CD4 ${ }^{+} \mathrm{T}$ cells. The frequency of variant cells was calculated as the number of cells in the window divided by the total number of $\mathrm{CD} 4^{+} \mathrm{T}$ cells.

\section{RT-PCR}

Total RNA was extracted from 1 to $5 \times 10^{6} \mathrm{~T}$ cells with RNAzol B (Tel-test Inc., Friendswood, Texas) following the manufacturer's instructions. First-strand cDNA was synthesized using oligo $\mathrm{d}(\mathrm{T})$ and Maloney murine leukemia virus-RT (Promega Corporation, Madison, Wisconsin) in 20- $\mu$ l final volume, and $1 \mu$ l was used in each PCR reaction. The primers were as follows: $\beta$-actin forward 5', ACACTGTGCCCATCTACGAGGGG; $\beta$-actin reverse 5', ATGATGGAGTTGAAGGTAGTITCGTGGAT; RAG-1 forward 5', CCAAATTGCAGACATCTCAAC (corresponding to the 5' untranslated sequence); RAG-1 reverse 5', CAACATCTGCCTTCACATCGATCC (corresponding to the coding region); RAG1-F nested 5', CAGCCTGCTGAGCAAGGTAC; RAG-2 forward 5', ATACCTGGTT- 
TAGCGGCAAA (corresponding to the 5 ' untranslated sequence); RAG-2 reverse 5', TGGTGTITCCCTCCATGGATG (corresponding to the coding region); RAG2-R nested 5', AAGAGGAGGGAGGTAGCAGG; TdT forward and TdT-R nested were as published (Meffre et al, 2000); and TdT reverse 5', AAAGTGGTTCTTCTCTGACA. The RAG-1 and RAG-2 primers span the single intron within the RAG-1 and RAG-2 genes. The TdT primers span introns I and II of the corresponding gene.

\section{Blotting and Oligotyping}

PCR products were separated by $1.5 \%$ agarose gel electrophoresis and alkali-blotted onto Hybond- $\mathrm{N}^{+}$ membrane (Amersham, Arlington Heights, Illinois). Filters were prehybridized in BLOTTO solution (6× SSC, $1 \%$ milk, 5 mm EDTA, $0.1 \%$ SDS) at $42^{\circ} \mathrm{C}$ for 3 hours and hybridized overnight at $42^{\circ} \mathrm{C}$ to internal oligonucleotide probes with the following sequence: RAG-1 5', CAGTTCTGCCCCAGATGAAAT; RAG-2 5', TCAGCCAGGCTTCTCACTGA; and TdT 5', ACCCTTTCCTGCGGGCCAGCT.

\section{Ligation-Mediated PCR}

The assay was performed as previously described (Schlissel et al, 1993). The PCR samples were blotted, and filters were hybridized overnight at $37^{\circ} \mathrm{C}$ with the specific internal oligonucleotides. The primers were as follows: for the 5' D $\beta-1$ : 5', GCAGCTGCTCTGGTGGTC (first PCR); 5', TCTGGTGGTCTCTCCCAG (nested); 5', GGCTGTTITTGTACAAAGC (probe-1); 5', GTACAAAGCTGTAACATTGT (probe-2); for the $3^{\prime}$ D $\beta-1$ : 5', CTGACATGTGATCAGGAGTGA (first PCR); 5', AAGACCTGTGACCCAGGA (nested); 5', GAAGAGGACTCTGGGAGT (probe-1); 5', ACCTCTCTGGCGGTCCCAA (probe-2); for the 5' D $\beta-2$ : 5', CAGTCAGACTAACCTCTGCCA (first PCR); 5', GCTTCCTGCCGCTGCCCA (nested); 5', CTAGCAGGGAGGAAACATT (probe-1); 5', TTGTATCATGGTGTAACAT (probe-2); for the 3' D $\beta-2$ : 5', AAGACCACAGCTGGGACCA (first PCR); 5', CCCACCTGGTAGCTGCATT (nested); 5', ATGCTTACTGCATCAGGGTT (probe-1); 5', TGATTCAGGTAGAGGAGGT (probe-2). Control reactions to determine the relative amounts of DNA were performed with primers to the IL-5 gene: forward 5', GTGAAAGAGACCTTGGCACTG; and reverse 5', GGCAAAGTGTCAGTATGCCTG.

\section{Statistical Analysis}

Statistical analysis was performed using the Student's $t$ test. A probability value of $p<0.05$ was considered significant.

\section{Acknowledgements}

We thank Drs. Luisa Granziero, Institute for Cancer Research and Treatment, Candiolo, Italy and Alfredo Brusco, University of Turin, Italy for critical reading of the manuscript. We also thank the AT patients and their relatives for their generous participation in this research project.

\section{References}

Agrawal A, Eastman QM, and Schatz DG (1998). Transposition mediated by RAG1 and RAG2 and its implications for the evolution of the immune system. Nature 394:744-751.

Akiyama M, Kyoizumi S, Hirai Y, Kusunoki Y, Iwamoto KS, and Nakamura N (1995). Mutation frequency in human blood cells increases with age. Mutat Res 338:141-149.

Bakhshi A, Wright JJ, Graninger W, Seto M, Owens J, Cossman J, Jensen JP, Goldman P, and Korsmeyer SJ (1987). Mechanism of the $t(14 ; 18)$ chromosomal translocation: Structural analysis of both derivative 14 and 18 reciprocal partners. Proc Natl Acad Sci USA 84:2396-2400.

Barlow C, Eckhaus MA, Schaffer AA, and Wynshaw-Boris A (1999). Atm haploinsufficiency results in increased sensitivity to sublethal doses of ionizing radiation in mice. Nat Genet 21:359-360.

Bebb DG, Warrington PJ, de Jong G, Yu Z, Moffat JA, Skov K, Spacey S, Gelmon K, and Glickman BW (2001). Radiation induced apoptosis in ataxia telangiectasia homozygote, heterozygote and normal cells. Mutat Res 476:13-20.

Boultwood J (2001). Ataxia telangiectasia gene mutations in leukaemia and lymphoma. J Clin Pathol 54:512-516.

Delia D, Mizutani S, Panigone S, Tagliabue E, Fontanella E, Asada M, Yamada T, Taya Y, Prudente S, Saviozzi S, Frati L, Pierotti MA, and Chessa L (2000). ATM protein and p53serine 15 phosphorylation in ataxia-telangiectasia (AT) patients and at heterozygotes. $\mathrm{Br} \mathrm{J}$ Cancer 82:1938-1945.

Geoffroy-Perez B, Janin N, Ossian K, Lauge A, Croquette MF, Griscelli C, Debre M, Bressac-de-Paillerets B, Aurias A, Stoppa-Lyonnet D, and Andrieu N (2001). Cancer risk in heterozygotes for ataxia-telangiectasia. Int J Cancer 93:288293.

Giovannetti A, Mazzetta F, Caprini E, Aiuti A, Marziali M, Pierdominici M, Cossarizza A, Chessa L, Scala E, Quinti I, Russo G, and Fiorilli M (2002). Skewed T-cell receptor repertoire, decreased thymic output, and predominance of terminally differentiated $\mathrm{T}$ cells in ataxia telangiectasia. Blood 100:4082-4089.

Golub R (2002). V gene replacement in T and B lymphocytes: Illicit or regimented rearrangement? Arch Immunol Ther Exp (Warsz) 50:255-262.

Golub R, Huang CY, Kanagawa O, and Wu GE (2001). V $\alpha$ gene replacement in a TCR $\alpha$ knock-in mouse. Eur $\mathrm{J}$ Immunol 31:2919-2925.

Haluska FG, Finver S, Tsujimoto $Y$, and Croce CM (1986). The $\mathrm{t}(8 ; 14)$ chromosomal translocation occurring in B-cell malignancies results from mistakes in V-D-J joining. Nature 324:158-161.

Han S, Dillon SR, Zheng B, Shimoda M, Schlissel MS, and Kelsoe G (1997). V(D)J recombinase activity in a subset of germinal center B lymphocytes. Science 278:301-305.

Hiom K, Melek M, and Gellert M (1998). DNA transposition by the RAG1 and RAG2 proteins: A possible source of oncogenic translocations. Cell 94:463-470.

Hirota H, Kubota M, Adachi S, Okuda A, Lin YW, Bessho R, Wakazono Y, Matsubara K, Kuwakado K, Akiyama Y, and Tsutsui T (1994). Somatic mutations at T-cell antigen recep- 
tor and glycophorin A loci in pediatric leukemia patients following chemotherapy: Comparison with HPRT locus mutation. Mutat Res 315:95-103.

Isoda A, Yokohama A, Matsushima T, Tsukamoto N, Nojima $Y$, and Karasawa M (2002). The naive T-lymphocyte compartment is well preserved in patients with chronic myelogenous leukaemia in chronic phase. Br J Haematol 119:949-955.

Itoh K, Meffre E, Albesiano E, Farber A, Dines D, Stein P, Asnis SE, Furie RA, Jain RI, and Chiorazzi N (2000). Immunoglobulin heavy chain variable region gene replacement as a mechanism for receptor revision in rheumatoid arthritis synovial tissue B lymphocytes. J Exp Med 192:1151-1164.

Khanna KK (2000). Cancer risk and the ATM gene: A continuing debate. J Natl Cancer Inst 92:795-802.

Kyoizumi S, Akiyama M, Hirai Y, Kusunoki Y, Tanabe K, and Umeki S (1990). Spontaneous loss and alteration of antigen receptor expression in mature $\mathrm{CD}^{+} \mathrm{T}$ cells. J Exp Med 171:1981-1999.

Lantelme E, Mantovani S, Palermo B, Campanelli R, Granziero L, Monafo V, and Giachino C (2000a). Increased frequency of RAG-expressing, CD4 ${ }^{+} \mathrm{CD} 3^{\text {low }}$ peripheral $\mathrm{T}$ lymphocytes in patients with detective responses to DNA damage. Eur J Immunol 30:1520-1525.

Lantelme E, Palermo B, Granziero L, Mantovani S, Campanelli R, Monafo V, Lanzavecchia A, and Giachino C (2000b). RAG gene expression and $V(D) J$ recombination in $\mathrm{CD}^{+}{ }^{+} \mathrm{CD} 3^{\text {low }}$, mature T lymphocytes. J Immunol 164:34553459.

Lavin MF and Shiloh Y (1997). The genetic defect in ataxiatelangiectasia. Annu Rev Immunol 15:177-202.

Liao M-J and Van Dyke T (1999). Critical role for Atm in suppressing $\mathrm{V}(\mathrm{D}) \mathrm{J}$ recombination-driven thymic lymphoma. Genes Dev 13:1246-1250.

McMahan CJ and Fink PJ (1998). RAG reexpression and DNA recombination at $T$ cell receptor loci in peripheral $C D 4^{+}$ T cells. Immunity 9:637-647.

Meffre E, Davis E, Schiff C, Cunningham-Rundles C, Ivashkiv LB, Staudt LM, Young JW, and Nussenzweig MC (2000). Circulating human $B$ cells that express surrogate light chains and edited receptors. Nat Immunol 1:207-213.

Messier TL, O'Neill JP, Hou S-M, Nicklas JA, and Finette BA (2003). In vivo transposition mediated by $V(D) J$ recombinase in human T lymphocytes. EMBO J 22:1381-1388.

Neubauer S, Arutyunyan R, Stumm M, Dork T, Bendix R, Bremer M, Varon R, Sauer R, and Gebhart E (2002). Radiosensitivity of ataxia telangiectasia and Nijmegen breakage syndrome homozygotes and heterozygotes as determined by three-color FISH chromosome painting. Radiat Res 157: 312-321.

Paganelli R, Scala E, Scarselli E, Ortolani C, Cossarizza A, Carmini D, Aiuti F, and Fiorilli M (1992). Selective deficiency of $\mathrm{CD}^{+} / \mathrm{CD} 45 \mathrm{RA}^{+}$lymphocytes in patients with ataxiatelangiectasia. J Clin Immunol 12:84-91.

Papavasiliou F, Casellas R, Suh H, Qin XF, Besmer E, Pelanda R, Nemazee D, Rajewsky K, and Nussenzweig MC (1997). V(D)J recombination in mature B cells: A mechanism for altering antibody responses. Science 278:298-301.

Petiniot LK, Weaver Z, Barlow C, Shen R, Eckhaus M, Steinberg SM, Ried T, Wynshaw-Boris A, and Hodes RJ (2000). Recombinase-activating gene (RAG) 2-mediated
$V(D) J$ recombination is not essential for tumorigenesis in Atm-deficient mice. Proc Natl Acad Sci USA 97:6664-6669.

Pittet MJ, Speiser DE, Valmori D, Cerottini JC, and Romero P (2000). Cutting edge: Cytolytic effector function in human circulating $\mathrm{CD}^{+} \mathrm{T}$ cells closely correlates with CD56 surface expression. J Immunol 164:1148-1152.

Rabbitts TH (1994). Chromosomal translocations in human cancer. Nature 372:143-149.

Radic MZ, Erikson J, Litwin SL, and Weigert M (1993). B lymphocytes may escape tolerance by revising their antigen receptors. J Exp Med 177:1165-1173.

Radic MZ and Zouali M (1996). Receptor editing, immune diversification, and self-tolerance. Immunity 5:505-511.

Rajewsky K (1998). Burnet's unhappy hybrid. Nature 394: 624-625.

Schlissel M, Constantinescu A, Morrow T, Baxter M, and Peng A (1993). Double-strand signal sequence breaks in $\mathrm{V}(\mathrm{D}) \mathrm{J}$ recombination are blunt, 5'-phosphorylated, RAGdependent, and cell cycle regulated. Genes Dev 7:25202532.

Schubert R, Reichenbach J, and Zielen S (2002). Deficiencies in $\mathrm{CD}^{+}$and $\mathrm{CD}^{+} \mathrm{T}$ cell subsets in ataxia telangiectasia. Clin Exp Immunol 129:125-132.

Shiloh Y (1997). Ataxia-telangiectasia and the Nijmegen breakage syndrome: Related disorders but genes apart. Annu Rev Genet 31:635-662.

Smilenov LB, Brenner DJ, and Hall EJ (2001). Modest increased sensitivity to radiation oncogenesis in ATM heterozygous versus wild-type mammalian cells. Cancer Res 61:5710-5713.

Stoppa-Lyonnet D, Soulier J, Lauge A, Dastot H, Garand R, Sigaux F, and Stern MH (1998). Inactivation of the ATM gene in T-cell prolymphocytic leukemias. Blood 91:3920-3926.

Stumm M, Neubauer S, Keindorff S, Wegner RD, Wieacker P, and Sauer R (2001). High frequency of spontaneous translocations revealed by FISH in cells from patients with the cancer-prone syndromes ataxia telangiectasia and Nijmegen breakage syndrome. Cytogenet Cell Genet 92:186-191.

Su Y and Swift M (2000). Mortality rates among carriers of ataxia-telangiectasia mutant alleles. Ann Intern Med 133: $770-778$

Swift M (2001). Public health burden of cancer in ataxiatelangiectasia heterozygotes. J Natl Cancer Inst 93:84-85.

Swift M, Morrell D, Massey RB, and Chase CL (1991). Incidence of cancer in 161 families affected by ataxiatelangiectasia. N Engl J Med 325:1831-1836.

Taylor AM, Metcalfe JA, Thick J, and Mak Y-F (1996). Leukemia and lymphoma in ataxia telangiectasia. Blood 87:423-438

Tiegs SL, Russell DM, and Nemazee D (1993). Receptor editing in self-reactive bone marrow B cells. J Exp Med 177:1009-1020.

Tycko B and Sklar J (1990). Chromosomal translocations in lymphoid neoplasia: A reappraisal of the recombinase model. Cancer Cells 2:1-8.

Vorechovsky I, Luo L, Dyer MJ, Catovsky D, Amlot PL, Yaxley JC, Foroni L, Hammarstrom L, Webster AD, and Yuille MA (1997). Clustering of missense mutations in the ataxia- 
telangiectasia gene in a sporadic T-cell leukaemia. Nat Genet 17:96-99.

Watts JA, Morley M, Burdick JT, Fiori JL, Ewens WJ, Spielman RS, and Cheung VG (2002). Gene expression phenotype in heterozygous carriers of ataxia telangiectasia. Am J Hum Genet 71:791-800.

West CM, Elyan SA, Berry P, Cowan R, and Scott D (1995). A comparison of the radiosensitivity of lymphocytes from normal donors, cancer patients, individuals with ataxiatelangiectasia $(\mathrm{A}-\mathrm{T})$ and $\mathrm{A}-\mathrm{T}$ heterozygotes. Int $\mathrm{J}$ Radiat Biol 68:197-203.
Xu Y and Baltimore D (1996). Dual roles of ATM in the cellular response to radiation and in cell growth control. Genes Dev 10:2401-2410.

Yuille MA, Coignet LJ, Abraham SM, Yaqub F, Luo L, Matutes E, Brito-Babapulle V, Vorechovsky I, Dyer MJ, and Catovsky D (1998). ATM is usually rearranged in T-cell prolymphocytic leukaemia. Oncogene 16:789-796. 